\title{
HUBUNGAN PROFESIONALITAS DAN AKUNTABILITAS PENGELOLAAN ZAKAT TERHADAP EFEKTIVITAS PEMBERDAYAAN EKONOMI UMAT
}

\author{
PROFESSIONALITY RELATIONSHIP AND ACCOUNTABILITY OF ZAKAT MANAGEMENT \\ TOWARD THE EFFECTIVENESS OF GENERAL ECONOMIC EMPOWERMENT
}

\author{
Muhammad Alfi Alhubbufillah")1, Didin Hafidhuddin"*), dan Hendri Tanjung ${ }^{* * *}$ ) \\ *) Sekolah Bisnis, Institut Pertanian Bogor \\ Jl. Raya Pajajaran, Bogor 16151 \\ $\left.{ }^{* *}\right)$ Departemen Ekonomi, Fakultas Ekonomi dan Manajemen, Institut Pertanian Bogor \\ Jl. Kamper, Kampus IPB Dramaga, Bogor 16680 \\ $\left.{ }^{* * *}\right)$ Universitas Ibn Khaldun (UIKA) \\ Jl. Baru, Kedung Badak, Tanah Sareal, Bogor 16162
}

\begin{abstract}
The objectives of this research were 1) to analyze the correlation of amil zakat professionalism and accountability of zakat management to the effectiveness of economic empowerment in LAZ Daarut Tauhiid Bogor; 2) to analyze inhibiting and supporting factors from the effectiveness of empowerment spirit in LAZ Daarut Tauhiid Bogor. This research used probability sampling and simple random sampling technique to provide equal chances for each random respondent without looking at the strata of the population. The number of respondents was 159 mustahik. This research used SEM model (Structure Equation Model) to support three simultaneous activities; i.e. checking the validity and instrument reliability (confirmatory factor analysis), testing correlation model on latent variables (path analysis), and getting a model useful for forecasting (equipped with structural model and regression analysis). The results of this research showed that the value of Amil Zakat Professionalism was 0.600, and the value of Zakat Management Accountability was 0.440. Amil Zakat Professionalism Variable (X1) and Zakat Management Accountability (X2) on endogenous variables of the Effectiveness of Community Economic Empowerment (Y) with a value of 0.920 or $92 \%$, and $8 \%$ compared to other factors outside the model.
\end{abstract}

Keywords: professional, accountability, effectiveness, economic empowerment, zakat

\begin{abstract}
Abstrak: Tujuan penelitian ini 1) menganalisis hubungan antara profesionalitas amil zakat dan akuntabilitas pengelolaan zakat terhadap efektivitas pemberdayaan ekonomi umat pada LAZ Daarut Tauhiid Bogor, 2) menganalisis faktor penghambat dan faktor pendukung dari efektivitas pemberdayaan umat pada LAZ Daarut Tauhiid Bogor. Metode pengambilan sampel yang digunakan, yaitu probability sampling dengan teknik pengambilan sampel, yaitu simple random sampling dimana memberi peluang yang sama bagi setiap responden secara acak tanpa melihat strata dalam populasi. Jumlah sampel responden sebanyak 159 mustahik. Dalam penelitian ini digunakan Model SEM (Structure Equation Model) karena mendukung tiga kegiatan secara serempak, yaitu pemeriksaan validitas dan reliabilitas instrumen (setara dengan faktor analisis konfirmatori), pengujian model hubungan antar variabel laten (setara dengan analisis Path) dan mendapatkan model yang bermanfaat untuk prakiraan atau peramalan (setara dengan model struktural atau analisis regresi). Hasil dari penelitian ini adalah nilai profesionalitas amil zakat sebesar 0,600 dan nilai akuntabilitas pengelolaan zakat sebesar 0,440. Adapun terdapat hubungan yang signifikan dari keseluruhan variabel eksogen profesionalitas amil zakat (X1) dan akuntabilitas pengelolaan zakat (X2) terhadap variabel endogen efektifitas pemberdayaan ekonomi umat (Y) dengan nilai sebesar 0,920 atau sebesar $92 \%$ adapun $8 \%$ dipengaruhi oleh faktor lain diluar model.
\end{abstract}

Kata kunci: profesional, akuntabilitas, efektivitas, pemberdayaan ekonomi, zakat

\footnotetext{
${ }^{1}$ Alamat Korespondensi:

Email: muhammadalfi91@gmail.com
} 


\section{PENDAHULUAN}

Berdasarkan data dari Badan Pusat Statistik (BPS, 2017) penduduk di Kabupaten Bogor Tahun 2017 berjumlah kurang lebih sebanyak 5,7 juta jiwa dimana kegiatan utama mereka yang terbesar $35,05 \%$, yaitu penduduk usia kerja, 22,64\% angkatan kerja dan 20,72\% bekerja. Adapun tingkat pengangguran sebesar $1,92 \%$ dan bukan angkatan kerja sebesar $12,41 \%$.

Data BPS (2017) menunjukkan jumlah penduduk miskin dan persentasenya terjadi peningkatan yang cukup signifikan dimana tahun 2013 sebesar 451.000 jiwa (9,45\%), 2014 sebesar 479.100 jiwa (8,99\%), 2015 sebesar 487.100 jiwa (8,92\%), 2016 sebesar 490.800 jiwa (8,78\%), 2017 sebesar 487.280 jiwa (8,53\%). Salah satu penyebab masih tingginya angka kemiskinan adalah bahwa dana zakat yang disalurkan masih banyak yang hanya sekedar untuk konsumtif sesaat. Oleh karena itu, menurut Kholiq (2012) model penggunaan zakat yang efisien untuk pemberdayaan ekonomi kaum miskin alangkah baiknya dilakukan dalam bentuk modal untuk pengembangan bisnis dan membantu merintis bisnis baru. Data ini menginformasikan bahwa tingkat hidup penduduk miskin khususnya di Kabupaten Bogor masih tinggi, yaitu $8,53 \%$. Analisis evaluasi menggunakan data BPS menghasilkan kesimpulan bahwa kemiskinan di Kabupaten Bogor masih tinggi sehingga diperlukan program pemberdayaan yang efektif khususnya melalui LAZ. Hasil laporan BAZNAS Kabupaten Bogor tanggal 5 Februari 2018 bahwa selama ini BAZNAS telah mengumpulkan zakat sekabupaten Bogor sebesar Rp6 Miliar. Hal ini tidak sesuai dengan potensi di Kabupaten Bogor, yaitu sebesar Rp15Miliar/tahun (DPMPTSP, 2018). Beik (2009) di dalam penelitiannya mengatakan bahwa zakat mampu mengurangi jumlah keluarga miskin dari $84 \%$ menjadi $74 \%$. Melihat potensi yang sangat besar itu maka banyak sekali dampak positif zakat sebagaimana menurut Abdullah dan Suhaib (2011) bahwa banyak penelitian telah membuktikan dampak positif zakat pada kehidupan sosial masyarakat muslim. Apriansyah (2011) menambahkan dengan mengatakan bahwa program penyaluran dana zakat harus lebih difokuskan pada fakir miskin. Oleh karena itu, peran muzaki sangatlah penting untuk mengurangi tingkat kemiskinan. Mukhlis dan Beik (2013) yang mengatakan bahwa diketahui sejumlah faktor yang membuat seseorang mau untuk membayar zakat adalah faktor keagamaan seperti iman, pemahaman agama, dan balasan, lalu ada juga faktor-faktor lainnya seperti kepedulian sosial, kepuasan diri, dan organisasi.
Bakar (2011) yang mengatakan bahwa distribusi zakat akan dapat terjadi dalam dua situasi, pertama adalah distribusi langsung dalam bentuk dukungan seumur hidup yang diberikan kepada mereka yang tidak produktif karena mereka tidak mampu bekerja dan mencari cara untuk mempertahankan hidup mereka. Situasi kedua adalah dana zakat menjadi sumber daya untuk melakukan kegiatan yang dapat digunakan untuk mendatangkan pendapatan yang dapat meningkatkan kehidupan para mustahik. Dengan potensi yang besar tersebut maka dibutuhkan profesionalitas di dalam mengelola dana zakat termasuk didalamnya adalah mengenai pendistribusiannya, menurut Andriyanto (2011) tentang profesionalitas pengelolaan zakat, menurutnya dalam Islamupaya pengentasankemiskinan adalah dengan zakat. Oleh karena itu, zakat seharusnya dikelola secara produktif dan profesional sehingga zakat dapat mengambil bagian dalam merealisasikan ide-ide Islam untuk mensejahterakan masyarakat. Adapun bila dipandang dari perspektif muzakki menurut Ayuniyyah (2011) mengatakan bahwa sedikitnya terdapat enam faktor penting yang dapat memberikan kepuasan kepada muzakki, yaitu pencairan (pengeluaran) zakat yang sama, petugas amil yang terinformasi dengan baik, profesionalisme petugas amil, kemudahan proses pengumpulan zakat, distribusi zakat, dan sertifikat pemerintah.

Tetapi, permasalahanya adalah amil sebagai sumberdaya manusia pada umumnya masih rendah baik dilihat dari kemampuan keterampilan (skill), pengetahuan (knowledge), dan perilaku (attitude) maupun kemampuan teknis di bidang perencanaan dan pelaksanaan pemberdayaan umat, yang antara lain disebabkan oleh rendahnya tingkat pendidikan formal serta kurangnya pelatihan yang dimiliki oleh sebagian amil zakat. Walaupun susunan struktur amil zakat terlihat lengkap, tetapi sebagian pengurus tidak atau kurang aktif melaksanakan tugas dan fungsinya atau tidak terkonsentrasi dalam pelaksanaan tugas pokok dan fungsinya.

Berkaitan dengan menggali potensi zakat, menurut Hafidhuddin (2011) didalam jurnalnya mengatakan bahwa untuk menggali potensi zakat tersebut, paling tidak diperlukan empat langkah yang harus dilakukan secara simultan, yaitu sosialisasi dan edukasi kepada masyarakat terkait dengan hukum dan hikmah zakat, penguatan amil zakat, penyaluran zakat yang tepat sasaran sesuai dengan ketentuan syariah, dan saling bersinergi serta koordinasi atau taawun antar sesama 
amil zakat (tingkat daerah, nasional, regional, dan internasional). Dengan mengacu pada langkah-langkah tersebut dalam menggali potensi zakat tentunya diharapkan amil dapat memaksimalkan potensi zakat modern kini sebagaimana dikatakan oleh Karim dan Syarief (2009) bahwa dalam pengelolaan zakat modern, amil memiliki posisi yang sangat penting dalam mengemas program-program atau produk yang berdayaguna bagi mustahiq (orang yang berhak menerima zakat). Semua ini tentunya ditujukan semata-mata agar meningkatkan kepercayaan muzaki untuk menyalurkan dana zakatnya kepada LAZ guna memaksimalkan penyaluran zakat secara merata, karena menurut Miftah (2008) bahwa masih banyak ditemukan beberapa muzaki menyalurkan dana zakatnya tidak melalui lembaga amil zakat melainkan diberikan secara individu ke sejumlah masyarakat miskin dalam bentuk amal.

Landasan teori yang diambil untuk mengukur berbagai variabel didalam penelitian ini adalah sebagai berikut: Untuk menganalisis profesionalitas landasan teori yang digunakan, yaitu Ratminto dan Atik (2012) yang mengatakan bahwa profesionalitas dapat dilihat dari beberapa aspek diantaranya komitmen dan konsistensi, wewenang dan tanggung jawab, integritas, ketepatan dan kecepatan, disiplin kerja, serta penguasaan ilmu pengetahuan dan teknologi. Untuk menganalisis akuntabilitas landasan teori yang digunakan, yaitu Ellwood (2009) yang mengatakan bahwa bentukbentuk akuntabilitas yaitu akuntabilitas hukum dan peraturan, akuntabilitas proses, akuntabilitas program, serta akuntabilitas kebijakan. Begitupun untuk menganalisis tingkat efektivitas maka landasan teori yang digunakan, yaitu Duncan yang dikutip Steers (2010) yang mengatakan bahwa efektivitas dapat diukur berdasarkan tiga indikator yaitu pencapaian tujuan, integrasi, serta adaptasi.

Pada penelitian terdahulu oleh Indriati (2015), ditemukan ada beberapa faktor pendukung efektifitas pendayagunaan zakat dimana berupa penyusunan program dalam rangka pelaksanaan operasional dan mengevaluasi jalannya program. Dalam menarik simpati muzaki untuk mempercayakan pengelolaan dana zakat oleh LAZ perlu memperhatikan faktor berikut, menurut Salihati (2010), dimentions of marketing mix pada suatu organisasi, yaitu berupa produk, harga, tempat, promosi, orang, proses, dan bukti fisik. Berdasarkan hasil penelitian Coryna dan
Tanjung (2015) yang mengatakan bahwa saat ini banyak sekali tokoh masyarakat yang pro pembayaran zakat melalui amil dan tingginya tingkat pertumbuhan kelas menengah muslim Indonesia. Hasil penelitian Ibrahim (2008) menyarankan bahwa perlunya rencana tindakan komprehensif untuk memastikan efektivitas distribusi zakat dalam meningkatkan ekonomi umat. Rencana aksi komprehensif membutuhkan kerja sama dan komitmen serius dari tiga pihak penting, yaitu lembaga zakat, penerima zakat, dan pemerintah. Dari hasil penelitian Sutomo et al. (2017) yang mengatakan bahwa terdapat empat dimensi yang berpengaruh terhadap kepuasan muzakki yang ditunjukkan dengan besarnya kontribusi yang diberikan. Keempat dimensi tersebut ialah assurance, compliance, empathy, dan reliability. Hasil penelitian Lessy (2009) menunjukkan bahwa untuk mengoptimalkan kinerja diantara lembaga zakat pemerintah maupun swasta, diperlukan mempertimbangkan manfaat bagi kedua belah pihak yaitu dengan berkolaborasi untuk mengentaskan kemiskinan.

Tujuan penelitian ini adalah menganalisis hubungan antara profesionalitas amil zakat dan akuntabilitas pengelolaan zakat terhadap efektivitas pemberdayaan ekonomi umat pada LAZ Daarut Tauhiid Bogor. Di samping itu, menganalisis faktor penghambat dan faktor pendukung dari efektivitas pemberdayaan umat pada LAZ Daarut Tauhiid Bogor.

\section{METODE PENELITIAN}

Penelitian ini mengambil studi kasus pada LAZ Daarut Tauhiid Bogor. Sampel penelitian ini adalah mustahik yang menerima bantuan dana zakat dari LAZ Daarut Tauhiid Kabupaten Bogor. Penelitian ini mengambil sampel sebanyak 159 mustahik. Kategori mustahik dalam penelitian ini yaitu fakir dan miskin (yang mempunyai usaha kecil dan memiliki kemauan merubah perekonomiannya) yang menerima bantuan dana zakat produktif. Tabel 1 menunjukkan besaran jumlah penyataan yang diajukan kepada reponden melalui angket yang disebar oleh peneliti. Jumlah pernyataan diajukan dengan bobot yang sama dari masing-masing variabel laten agar memperoleh hasil yang signifikan. Periode pengambilan angket/kuisioner dalam penelitian ini dimulai sejak Mei 2018 hingga Agustus 2018. 
Metode penelitian yang dilakukan dalam penelitian ini termasuk dalam jenis penelitian kuantitatif dengan pendekatan desktiptif. Untuk keperluan analisis data, penelitian ini menggunakan model SEM (Structure Equation Model) melalui software Lisrel (Linear Structural Relationship). Selanjutnya, data yang dipergunakan dalam kajian ini adalah data primer dan data sekunder yang bersifat kuantitatif dan kualitatif. Pengumpulan data meliputi: studi kepustakaan, pengamatan langsung ke lapangan, membuat daftar pertanyaan (kuesioner), dan wawancara dengan manajemen LAZ, dan mustahik zakat LAZ Daarut Tauhiid, dan Observasi (data yang diperoleh dari pengamatan di lapangan sebelum penelitan maupun sesudah penelitian).

Merujuk pada Tabel 2, jumlah total keseluruhan populasi sebesar 264 orang. Metode pengambilan sampel yang digunakan dalam penelitian ini adalah probability sampling dengan menggunakan simple random sampling. Rumus Slovin, yaitu $\mathrm{n}=\mathrm{N} /\left(1+\mathrm{Ne}^{2}\right)$ dengan n (Jumlah Sampel); N (Jumlah Populasi); e (Nilai presisi yang ditetapkan atau tingkat kesalahan $5 \%)$.

$$
\begin{gathered}
\mathrm{n}=264 /\left(1+264(0,05)^{2}\right)=159,04=159 \text { orang } \\
\lambda^{2} \text { dengan } \mathrm{dk}=1, \text { taraf kesalahan } 5 \% \\
\mathrm{P}=\mathrm{Q}=0,5 \mathrm{~d}=0,05 . \mathrm{s}=\text { jumlah sampel }
\end{gathered}
$$

Dalam penelitian ini untuk menetukan sampel digunakan rumus Slovin. Berdasarkan kepada perhitungan dengan menggunakan rumus di atas maka diperoleh hasil dari 264 populasi dengan tingkat kesalahan $5 \%$ adalah 159 . Jumlah sampel ini diharapkan dapat mewakili hasil penelitian ini. Adapun alat ukur penelitian menggunakan Skala Likert sebagaimana di Tabel 3.

Tabel 1. Variabel Penelitian

\begin{tabular}{lllcc}
\hline Keterangan & Konstruk/ variabel laten & Dimensi konstruk/indikator/ variabel manifest & Kode & Jumlah pernyataan \\
\hline Variabel & Profesionalitas amil zakat & Komitmen dan konsisten & X11 & 3 \\
eksogen & & Wewenang dan tanggungjawab & X12 & 3 \\
& & Integritas & X13 & 3 \\
& & Ketepatan dan kecepatan & X14 & 3 \\
& & Disiplin kerja & X15 & 3 \\
& & Penguasaan ilmu pengetahuan dan teknologi & X16 & 3 \\
& Akuntabilitas & Akuntabilitas hukum dan peraturan & X21 & 4 \\
& pengelolaan zakat & Akuntabilitas proses & X22 & 4 \\
Variabel & & Akuntabilitas program & X23 & 4 \\
endogen & Eektivitas & Akuntabilitas kebijakan & X24 & 4 \\
& umat & Pencapaian tujuan & Y1 & 5 \\
& & Integrasi & Y2 & 5 \\
\hline
\end{tabular}

Tabel 2. Populasi

\begin{tabular}{lllc}
\hline Program Zakat Produktif & Pekerjaan & Jenis Pelatihan & Sasaran Populasi \\
\hline Program Balai Kreatif Skill & IRT, pelajar & Jahit & 20 \\
Oriented & IRT, Pelajar & Jahit dan Sablon & 30 \\
& IRT, Mahasiswa & Jahit & 20 \\
Gerobak Barokah & Baso, cilok, gorengan & & 31 \\
& Bubur ayam & 68 \\
Sayuran & Pedagang Kecil & & 66 \\
Program Desa Ternak & Domba & 4 \\
\hline & Jumlah Penerima Zakat \& Pelatihan & 25 \\
\hline
\end{tabular}


Berdasarkan rumusan masalah maka terdapat dua hipotesis yang diuji pada penelitian ini (Gambar 1), yaitu Hubungan antar variabel (terdapat hubungan antara profesionalitas amil zakat terhadap efektivitas pemberdayaan ekonomi umat; terdapat hubungan antara akuntabilitas pengelolaan zakat terhadap efektivitas pemberdayaan ekonomi umat; terdapat hubungan antara profesionalitas amil zakat dan akuntabilitas pengelolaan zakat secara bersama-sama terhadap efektivitas pemberdayaan ekonomi umat) dan terdapat faktor penghambat dan faktor pendukung dari efektivitas pemberdayaan ekonomi umat pada LAZ Daarut Tauhid di Kabupaten Bogor. Gambaran secara umum mengenai kerangka pemikiran penelitian ini selengkapnya pada Gambar 2.

\section{HASIL}

Hubungan Antara Profesionalitas Amil Zakat dan Akuntabilitas Pengelolaan Zakat terhadap Efektivitas Pemberdayaan Ekonomi Umat pada LAZ DT Bogor

Analisis Instrumen Data

Konstruk dalam penelitian ini berbentuk Unidimensional. Adapun untuk menguji signifikanitas dan reliabilitas konstruknya menggunakan apa yang disebut First Order Confirmatory Factor Analysis. Penggunaan konstruk tersebut bertujuan mengetahui rata-rata jawaban responden berdasarkan pertanyaan yang disebar dalam angket kuesioner. Dari jumlah pertanyaan yang disebar, terdapat rata-rata jawaban yang diperoleh dari para responden yang dipaparkan selengkapnya pada Tabel 4.

Tabel 3. Alat ukur instrumen angket penelitian skala Likert

\begin{tabular}{ccccc}
\hline \multicolumn{2}{c}{ Pengukuran Instrumen } & \multicolumn{2}{c}{ Rentang Nilai Instrumen } \\
\hline Nilai & Keterangan & Nilai & Keterangan & Rentang $\%$ \\
\hline 5 & Selalu & 1 & Sangat Rendah & $0-19$ \\
4 & Sering & 2 & Rendah & $20-39$ \\
3 & Kadang-Kadang & 3 & Sedang & $40-59$ \\
2 & Pernah & 4 & Tinggi & $60-79$ \\
1 & Tidak Pernah & 5 & Sangat Tinggi & $80-100$ \\
\hline
\end{tabular}

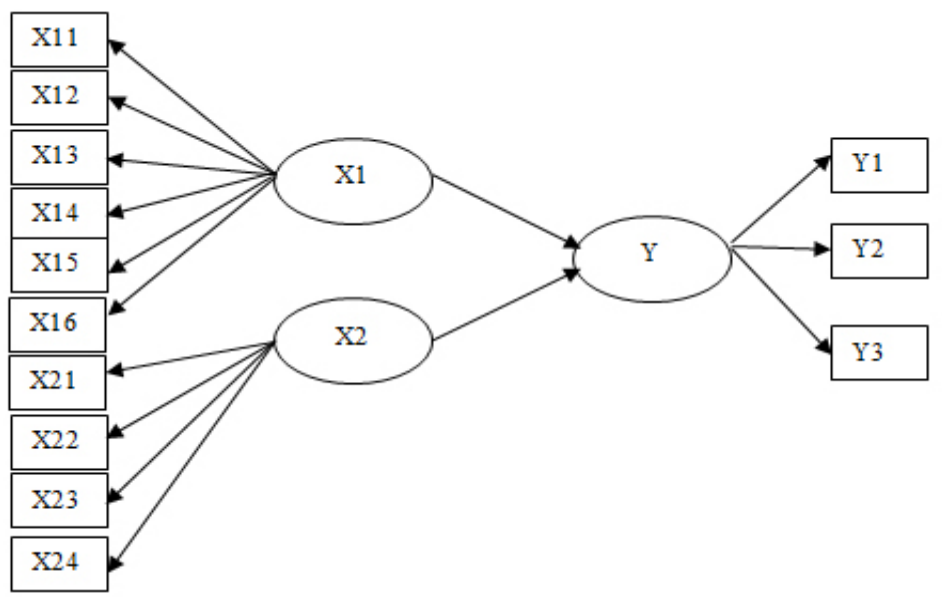

Gambar 1. Model teoritis atau kontruksi variabel 




Gambar 2. Kerangka pemikiran penelitian

Tabel 4. Kontruksi first order confirmatory factor analysis

\begin{tabular}{lllcc}
\hline Keterangan & Konstruk/Variabel Laten & Dimensi Konstruk/ Indikator/ Variabel Manifest & Kode & Rerata jawaban \\
\hline Variabel & Profesionalitas amil zakat & Komitmen dan konsisten & X11 & 4,2 \\
eksogen & (X1) & Wewenang dan tanggungjawab & X12 & 4,3 \\
& & Integritas & X13 & 4,4 \\
& & Ketepatan dan kecepatan & X14 & 4,2 \\
& & Disiplin kerja & X15 & 4,3 \\
& & Penguasaan ilmu pengetahuan dan teknologi & X16 & 4,5 \\
& \multirow{4}{*}{ Akuntabilitas } & Akuntabilitas hukum dan peraturan & X21 & 4,2 \\
& pengelolaan zakat (X2) & Akuntabilitas proses & X22 & 4,3 \\
& & Akuntabilitas program & X23 & 4,2 \\
& & Akuntabilitas kebijakan & X24 & 4,1 \\
Variabel & Efektivitas & Pencapaian tujuan & Y1 & 4,2 \\
endogen & pemberdayaan ekonomi & Integrasi & Y2 & 4,2 \\
& umat (Y) & Adaptasi & Y3 & 4,4 \\
\hline
\end{tabular}

Uji Signifikanitas dan Reliabilitas

Berdasarkan data yang dipaparkan pada Tabel 5, dapat disimpulkan variabel eksogen profesionalitas amil zakat bahwa signifikanitas tertinggi terletak pada dimensi disiplin kerja dengan nilai sebesar 0,800 dan terendah pada dimensi komitmen dan konsisten yakni sebesat 0,580 terhadap variabel profesionalitas amil zakat (X1). Nilai CR diperoleh sebesar 0,860 lebih tinggi dari 0,700 .
Berdasarkan data Tabel 5, dapat disimpulkan variabel eksogen akuntabilitas pengelolaan zakat bahwa signifikanitas tertinggi terletak pada dimensi akuntabilitas proses dengan nilai sebesar 0,950 dan terendah pada dimensi akuntabilitas kebijakan dengan nilai sebesar 0,510 terhadap variabel akuntabilitas pengelolaan zakat (X2). Nilai CR diperoleh sebesar 0,830 lebih tinggi dari 0,700 . 
Berdasarkan data Tabel 5, dapat disimpulkan variabel endogen efektivitas pemberdayaan ekonomi umat bahwa signifikanitas tertinggi menurut responden berdasarkan loading factor terletak pada dimensi integrasi dengan nilai sebesar 0,950 dan terendah pada dimensi pencapaian tujuan dengan nilai sebesar 0,670. Jika dinterpretasikan maka dimensi integrasi mempunyai hubungan yang paling kuat $(0,950)$ sedangkan dimensi pencapaian tujuan mempunyai hubungan yang kuat $(0,670)$ pada variabel efektifitas pemberdayaan ekonomi umat (Y). Sedangkan nilai CR diperoleh sebesar 0,890 lebih tinggi dari 0,700.

Analisa Data berdasarkan Goodness of Fit.

Berdasarkan Tabel 6, hasil pengolahan untuk pengujian goodness of fit menunjukkan kriteria p-value (chisquare) $0,068>0,05$ artinya model telah good fit. Selain itu, RMSEA menghasilkan nilai $0,049 \leq 0,08$. Artinya, model yang dihasilkan sudah good fit. Penggunaan kriteria goodness of fit yang lain, yaitu GFI, AGFI, IFI, CFI dan NFI menghasilkan nilai $>0,90$ yang artinya model yang dihasilkan sudah good fit. Hasil kesimpulan beberapa indikator menghasilkan kesimpulan model good fit sehingga pengujian hipotesis teori dapat dilakukan.

\section{Analisis Model Struktural (Structural Model Fit)}

Dari keseluruhan proses penelitian maka dihasilkan estimasi model SEM sebagaimana pada Tabel 7 menunjukkan bahwa nilai profesionalitas amil zakat (X1) sebesar 0,600 terhadap variabel Efektifitas pemberdayaan ekonomi umat (Y). Jadi, dapat disimpulkan bahwa semakin baik profesionalitas amil zakat maka efektifitas pemberdayaan ekonomi Umat semakin baik. Sedangkan nilai 0,600 mengandung nilai positif yang berarti mempunyai arah dan tujuan yang sama.

Tabel 5. Signifikanitas dan reliabilitas

\begin{tabular}{|c|c|c|c|c|c|c|}
\hline \multicolumn{2}{|c|}{ Variabel Laten } & \multirow{2}{*}{$\begin{array}{c}\text { SLF } \geq 0,30 \\
0,580\end{array}$} & \multirow{2}{*}{$\begin{array}{c}\text { tvalue } \geq 1,96 \\
10,07\end{array}$} & \multirow{2}{*}{$\begin{array}{c}\text { Error } \\
0,67\end{array}$} & \multirow{2}{*}{$\begin{array}{c}\text { Keterangan } \\
\text { Signifikan }\end{array}$} & \multirow[t]{2}{*}{$\mathrm{CR}$} \\
\hline $\mathrm{X} 11$ & Komitmen dan Konsisten & & & & & \\
\hline $\mathrm{X} 12$ & Wewenang dan Tanggungjawab & 0,680 & 15,66 & 0,54 & Signifikan & \\
\hline $\mathrm{X} 13$ & Integritas & 0,710 & 17,23 & 0,50 & Signifikan & 0,860 \\
\hline $\mathrm{X} 14$ & Ketepatan dan Kecepatan & 0,770 & 14,84 & 0,41 & Signifikan & \\
\hline $\mathrm{X} 15$ & Disiplin Kerja & 0,800 & 17,28 & 0,36 & Signifikan & \\
\hline \multirow[t]{2}{*}{$\mathrm{X} 16$} & Penguasaan Ilmu Pengetahuan dan Teknologi & 0,710 & 17,32 & 0,49 & Signifikan & \\
\hline & Jumlah & 4,25 & & 2,97 & & \\
\hline $\mathrm{X} 21$ & Akuntabilitas Hukum dan Peraturan & 0,550 & 14,23 & 0,70 & Signifikan & \\
\hline $\mathrm{X} 22$ & Akuntabilitas Proses & 0,950 & 23,81 & 0,09 & Signifikan & \\
\hline $\mathrm{X} 23$ & Akuntabilitas Program & 0,900 & 18,69 & 0,20 & Signifikan & 0,830 \\
\hline \multirow[t]{2}{*}{$\mathrm{X} 24$} & Akuntabilitas Kebijakan & 0,510 & 10,44 & 0,74 & Signifikan & \\
\hline & Jumlah & 2,91 & & 1,73 & & \\
\hline Y1 & Pencapaian Tujuan & 0,670 & 9,32 & 0,56 & Signifikan & \\
\hline Y2 & Integrasi & 0,950 & 8,18 & 0,10 & Signifikan & 0,890 \\
\hline Y3 & Adaptasi & 0,920 & 7,98 & 0,16 & Signifikan & \\
\hline
\end{tabular}

Tabel 6. Pengujian Goodness of fit Model SEM

\begin{tabular}{lccc}
\hline Goodness-of-Fit & Cutt-off-Value & Hasil & Kesimpulan \\
\hline p-value (chi-square) & $>0,05$ & 0,069 & Good fit \\
RMSEA & $\leq 0,08$ & 0,049 & Good fit \\
GFI & $>0,90$ & 0,990 & Good fit \\
AGFI & $>0,90$ & 0,970 & Good fit \\
IFI & $>0,90$ & 1,000 & Good fit \\
CFI & $>0,90$ & 1,000 & Good fit \\
NFI & $>0,90$ & 0,990 & Good fit \\
\hline
\end{tabular}


Tabel 7. Hasil estimasi model SEM

\begin{tabular}{lccc}
\hline Hubungan antar variabel & Koefisien jalur & $\mid$ t-hit $\mid$ & Kesimpulan \\
\hline $\begin{array}{l}\text { Profesionalitas amil zakat }(\mathrm{X} 1) \rightarrow \text { Efektifitas pemberdayaan } \\
\text { ekonomi umat (Y1) }\end{array}$ & 0,60 & 7,59 & Signifikan \\
$\begin{array}{l}\text { Akuntabilitas pengelolaan zakat }(\mathrm{X} 2) \rightarrow \text { Efektifitas } \\
\text { pemberdayaan ekonomi umat (Y1) }\end{array}$ & 0,44 & 5,42 & Signifikan \\
\hline
\end{tabular}

t-hitung $>$ t-tabel 1,96 dengan alpha 5\%

Nilai yang diperoleh akuntabilitas pengelolaan zakat (X2) sebesar 0,440 terhadap variabel efektifitas pemberdayaan ekonomi umat (Y). Jadi, dapat disimpulkan bahwa semakin baik akuntabilitas pengelolaan zakat maka efektifitas pemberdayaan ekonomi umat semakin baik. Sedangkan nilai 0,440 mengandung nilai positif yang berarti mempunyai arah dan tujuan yang sama.

Dari nilai regresi dari hubungan antara variabel X1 dan X2 dengan $\mathrm{Y}$ diperoleh nilai sebesar 0,920. Artinya terdapat hubungan yang signifikan antara variabel profesionalitas amil zakat (X1) dan variabel akuntabilitas pengelolaan zakat (X2) terhadap variabel efektifitas pemberdayaan ekonomi umat $(\mathrm{Y})$. Sedangkan nilai 0,920 mengandung nilai positif yang berarti mempunyai arah dan tujuan yang sama. Jadi kekuatan hubungannya sangat kuat tetapi variabel X1 lebih dominan dibandingkan dengan X2 .

R-square model sebesar $92 \%$ artinya persentase hubungan variabel profesionalitas amil zakat (X1) dan variabel akuntabilitas pengelolaan zakat (X2) terhadap variabel efektifitas pemberdayaan ekonomi umat (Y) sebesar $92 \%$ sedangkan sisanya $8 \%$ dijelaskan oleh faktor lain diluar model.

\section{Faktor Penghambat dan Faktor Pendukung}

Faktor pendukung kegiatan LAZ DT diantaranya Adanya kerjasama antara LAZ dengan Muzaki, Mustahik, pemasok bahan-baku, pemerintah setempat (RT, RW, Kelurahan) dan pihak lainnya yang membantu; Adanya motivasi dari mustahik untuk mendapatkan pengetahuan dan keterampilan; Adanya dorongan dari keluarga mustahik; Bersifat transparan dan memiliki tingkat kepercayaan yang baik antara pihak-pihak terkait. Faktor penghambat kegiatan LAZ DT diantaranya Keterbatasan pengetahuan dan keterampilan para amil; Permasalahan bagi mustahik yang memiliki usaha kecil, yaitu sepinya permintaan pasar pada bulan tertentu (musiman) dan rendahnya daya saing; Bagi amil yaitu masih adanya kelemahan di dalam pensosialisasian penggunaan dana zakat produktif kepada sebagian mustahik sehingga mereka memanfaatkan dana zakat produktif hanya untuk kegiatan konsumtifnya sesaat.

\section{Implikasi Manajerial}

Beberapa implikasi manajerial kepada pihak terkait tersebut diantaranya sebagaimana berikut: Pertama, bagi LAZ Daarut Tauhiid. Dari hasil penelitian ini terlihat bahwa profesionalitas para individu amil sangat berpengaruh besar di dalam proses pembinaan efektivitas pemberdayaan ekonomi para mustahik agar dapat meningkatkan daya saing mereka di masyarakat sehingga hasil akhirnya dapat meningkatkan segi perekonomian mereka. Tentunya profesionalitas SDM ini juga sangat diperlukan bagi LAZ DT sebagai modal LAZ dalam mengembangkan ide-ide mereka kedepan. Profesionalitas terhadap efektivitas dapat tercapai tentunya bilamana di dukung oleh sistem akuntabilitas pengelolaan zakat yang baik. Dengan demikian diperlukan peningkatan yang seimbang antara profesionalitas para individu amil dan juga peningkatan akuntabilitas proses pengelolaan zakat agar efektivitas pemberdayaan ekonomi umat semain membaik kedepannya. Kedua, bagi pemerintah khususnya BAZNAS sebagai badan pengelolaan zakat terbesar di Indonesia yang dimiliki oleh pemerintah. Dari hasil penelitian ini diharapkan dapat merangkul LAZ guna mesinergikan program kerja bersama agar mempercepat pencapaian tujuan mengentaskan kemiskinan khususnya di kabupaten Bogor secara merata dalam merespon setiap permasalahan para mustahik secara cepat dan tepat sasaran.

Dari pemantauan implikasi manajerial yang tidak kalah pentingnya adalah peran masyarakat itu sendiri dalam melancarkan proses kinerja para amil guna mengentaskan kemiskinan secara merata di masingmasing wilayah mereka. Selain itu masyarakat pun dapat ikut berkontribusi dalam program-program yang 
dilakukan Lembaga atau Badan Amil Zakat dalam memberikan informasi dan mendorong masyarakat lain untuk menjalankan kewajibannya mengeluarkan zakat agar dapat membantu mengurangi tingkat kemiskinan.

\section{KESIMPULAN DAN SARAN}

\section{Kesimpulan}

Profesionalitas para individu amil sangat berpengaruh besar di dalam proses pembinaan efektivitas pemberdayaan ekonomi para mustahik agar dapat meningkatkan daya saing mereka di masyarakat sehingga hasil akhirnya dapat meningkatkan segi perekonomian mereka. Tentunya profesionalitas SDM ini juga sangat diperlukan bagi LAZ DT sebagai modal LAZ dalam mengembangkan ide-ide mereka kedepan. Efisiensi profesionalitas terhadap efektivitas dapat tercapai tentunya bilamana di dukung oleh sistem akuntabilitas pengelolaan zakat yang baik. Dengan demikian diperlukan peningkatan yang seimbang antara profesionalitas para individu amil dan juga peningkatan akuntabilitas proses pengelolaan zakat agar efektivitas pemberdayaan ekonomi umat semain membaik kedepannya.

Kesimpulan yang didapatkan terbukti dan sejalan dengan teori yang berkaitan dengan tahapan pemberdayaan sebagaimana yang dinyatakan oleh Sulistiani (2017) bahwa ada tiga tahap pemberdayaan, yaitu tahap penyadaran dan pembentukan perilaku, tahap transformasi kemampuan wawasan, kecakapan dan keterampilan, serta tahap peningkatan kemampuan. Ketiga tahap pemberdayaan tersebut dapat ditemui di dalam diri amil zakat yang memiliki tingkat profesionalitas yang baik dengan didukung manajemen proses akuntabilitas pengelolaan zakat yang juga baik tentunya.

Faktor pendukung kegiatan LAZ DT diantaranya adanya kerjasama antara LAZ dengan Muzaki, Mustahik, pemasok bahan-baku, pemerintah setempat (RT, RW, Kelurahan) dan pihak lainnya yang membantu; Adanya motivasi dari mustahik untuk mendapatkan pengetahuan dan keterampilan; Adanya dorongan dari keluarga mustahik; Bersifat transparan dan memiliki tingkat kepercayaan yang baik antara pihak-pihak terkait. Sebaliknya, faktor penghambat kegiatan LAZ DT meliputi keterbatasan pengetahuan dan keterampilan para amil; Permasalahan bagi mustahik yang memiliki usaha kecil yaitu sepinya permintaan pasar pada bulan tertentu (musiman) dan rendahnya daya saing; Bagi amil yaitu masih adanya kelemahan di dalam pensosialisasian penggunaan dana zakat produktif kepada sebagian mustahik sehingga mereka memanfaatkan dana zakat produktif hanya untuk kegiatan konsumtifnya sesaat.

\section{Saran}

Terdapat beberapa cara dalam upaya perbaikan dan peningkatan efektifitas pemberdayaan ekonomi umat, diantaranya diperlukan penguatan kinerja pegawai LAZ DT dalam menjemput dan menyalurkan zakat kepada mustahik zakat agar dapat berdaya dan mandiri. Meningkatkan standar pelayanan minimal (SPM) baik kepada muzaki maupun mustahik. Selain itu, dari penelitian ini diharapkan dapat menjadi jalan pembuka khususnya bagi para peneliti selanjutnya untuk menggali lagi potensi kekuatan zakat di kabupaten Bogor guna memaksimalkan nilai efektivitas di dalam pemberdayaan ekonomi umat.

\section{DAFTAR PUSTAKA}

Abdullah M, Suhaib AQ. 2011. The impact of zakat on social life of muslim society. Pakistan Journal of Islamic Research 8:85-91.

Andriyanto. 2011. Strategi pengelolaan zakat dalam pengentasan kemiskinan. Jurnal Strategi Pengelolaan Zakat 19(1): 25-46. https://doi. org/10.21580/ws.19.1.211.

Apriansyah. 2011. Studi analisis kinerja Badan Amil Zakat (BAZ) Kota Bogor dalam meningkatkan jumlah usaha produktif para mustahiq. Jurnal Ekonomi Islam Al-Infaq 2(2): 81-97.

Ayuniyyah. 2011. Factors affecting zakat payment through institution of amil : muzaki perspectives analysis (case study of BAZNAS). Jurnal Ekonomi Islam Al-Infaq 2(2):49-64.

Bakar. 2011. Towards achieving the quality life in the management of zakat distribution to the rightful recipients (the poor and needy). International Journal of Business and Social Science 2(4): 237-245.

Beik IS. 2009. Analisis peran zakat dalam mengurangi kemiskinan : studi kasus Dompet Dhuafa. Jurnal Pemikiran dan Gagasan 2:2-12.

[BPS] Badan Pusat Statistik. 2017. Garis kemiskinan dan penduduk miskin Kabupaten Bogor periode 
2013-2017. Jakarta: Badan Pusat Statistik.

[BPS] Badan Pusat Statistik. 2017. Penduduk Usia 15 Tahun Ke Atas Menurut Jenis Kegiatan Tahun 2015-2017. Jakarta: Badan Pusat Statistik.

Coryna IA, Tanjung H. 2015. Formulasi strategi penghimpunan zakat oleh Badan Amil Zakat Nasional (BAZNAS). Jurnal Al-Muzara'ah. 3(2): 158-179. https://doi.org/10.29244/ jam.3.2.158-179.

[DPMPTSP] Dinas Penanaman Modal dan Pelayanan Terpadu Satu Pintu. 2018. Audiensi oleh pihak BAZNAS (Badan Amil Zakat Nasional) di DPMPTSP Kabupaten Bogor [internet]. [Diakses pada 2018 Agustus 15]. Tersedia pada http:// dpmptsp.bogorkab.go.id/auidiensi-oleh-pihakbaznas-di-dpmptsp-kabupaten-bogor/.

Ellwood S. 2009. Parish town and councils: financial accountability and management. Journal Local Government Studies 19:368-386. https://doi. org/10.1080/03003939308433687.

Hafidhuddin D. 2011. Peran srategis organisasi zakat dalam menguatkan zakat di dunia. Jurnal AlInfaq 2(1):1-4.

Ibrahim. 2008. Pembangunan ekonomi melalui tagihan zakat. Jurnal Syariah 16:223-244.

Indriati DS. 2015. Efektivitas Pendayagunaan Zakat di Provinsi Sulawesi Utara [disertasi]. Makassar: Universitas Islam Negeri Alauddin Makassar.

Karim AA, Syarief A. 2009. Fenomena unik di balik menjamurnya Lembaga Amil Zakat (LAZ) di Indonesia. Jurnal Pemikiran dan Gagasan 1(2009): 1-9.
Kholiq A. 2012. Pendayagunaan zakat, infak dan sedekah untuk pemberdayaan ekonomi masyarakat miskin di Kota Semarang. Jurnal Riptek 6(1):1-9.

Lessy Z. 2009. Zakat (alms-giving) management in Indonesia: whose job should it be ?. La Riba Jurnal Ekonomi Islam 3(1): 106-119. https:// doi.org/10.20885/lariba.vol3.iss1.art8.

Miftah AA. 2008. Pembaharuan zakat untuk pengentasan kemiskinan di Indonesia. Jurnal Innovation 7(14).

Mukhlis A, Beik IS. 2013. Analisis faktor-faktor yang memengaruhi tingkat kepatuhan membayar zakat: studi kasus Kabupaten Bogor. Jurnal al-Muzara'ah 1(1): 83-106. https://doi. org/10.29244/jam.1.1.83-106.

Ratminto, Atik. 2012. Manajemen Pelayanan. Yogyakarta: Pustaka Pelajar.

Salihati. 2010. An analysis of muzzaki's attitude and perception towards national zakat board in Jakarta [disertasi]. Bogor: Institut Pertanian Bogor.

Steers RM. 2010. Efektivitas Organisasi. Ed ke-47. Magdalena Jamin, penerjemah. Jakarta:Erlangga. Terjemahan dari Organizational Effectiveness, A Behavioral View. 48th Ed.

Sulistiani AT. 2017. Kemitraan dan Model-Model Pemberdayaan. Yogyakarta: Gava Media.

Sutomo, Najib M, Djohar S. 2017. Pengaruh kualitas pelayanan LAZ terhadap kepuasan dan loyalitas muzaki (studi kasus LAZ PKPU Yogyakarta). Jurnal Aplikasi Bisnis dan Manajemen 3(1): 5970.https://doi.org/10.17358/jabm.3.1.59. 